\title{
Strategies for Accurate Determination of Drift Characteristics of Unstable Gravimeter in Tropical, Coastal Environment
}

\author{
A. A. Okiwelu (Corresponding author) \\ Geophysics unit, Department of Physics \\ University of Calabar, Nigeria
}

Tel: 234-803-400-3637Ｅ-mail: okiwelu2000@yahoo.com

E. E. Okwueze

Geophysics unit, Department of Physics

University of Calabar, Nigeria

Tel: 234-803-543-2338 E-mail: emeka_okwueze@yahoo.com

I. B. Osazuwa

Department of Physics

Federal University of Petroleum Resources, Efurun, Nigeria

Tel: 234-803-590-4238Ｅ-mail: iosazuwa@yahoo.com

Received: September 28, 2011 Accepted: October 8, $2011 \quad$ Published: November 1, 2011

doi:10.5539/apr.v3n2p190

URL: http://dx.doi.org/10.5539/apr.v3n2p190

\begin{abstract}
The drift characteristics specific to an unstable gravimeter has been modeled to enhance high quality data that will be useful for gravimetric studies and to determine proper timing of field observations. A pre-field observation was carried out to monitor the tide and thus limiting the relative gravity observation to near-linear time window. Closed loop sequence technique of re-occupying a drift base compatible with the drift characteristics of the Lacoste and Romberg (model G446) and cascade model for the computation of drift were combined to obtain a more reliable data that fulfills the linear drift assumption. Subjecting the modelled drift to descriptive statistics a maximum value $(1.6550 \mathrm{mGal})$ and minimum value $(-0.3720 \mathrm{mGal})$ of drift were obtained. This variability in drift values and the disparity between the mean $(0.099 \mathrm{mGal})$ and the standard deviation $(0.2914 \mathrm{mGal})$ is a pointer to various factors that caused the instrumental drift. Such factors could be attributed to external temperature, age and usage of the gravimeter, mechanical stress and strain in the mechanism as the gravimeter is moved and subjected to vibrations. The low standard error of the mean $(0.0196 \mathrm{mGal})$ is a reflection of the validity of the linear drift assumption using the cascade model and the field procedure compatible with the drift characteristics of the gravimeter.
\end{abstract}

Keywords: Drift, Gravimeter, Cascade, Linear, Lacoste, Tide, Base

\section{Introduction}

The objective of most gravity surveys is to estimate the location and nature of subsurface structures. To achieve this goal field measurement must be converted to gravity data free of non-geological targets. Thus, the goal of processing gravity data is to identify and remove all factors not related to geologic features. Some of the initial stages in processing gravity data include the removal of temporary based effects in the earth's gravity field namely; instrumental drift and tidal effects. Instrumental drift is a phenomenon related to certain instrumental instabilities that cause the dial reading of gravimeter to change slowly with time even when acceleration of gravity remains constant. Gravimeters are very sensitive instruments and therefore, temperature changes and elastic creep in springs can cause reading to change gradually with time. Drift is complex. It is complex in the sense that it is specific to every gravimeter and could be a function of age, transportation. The amount of drift could be very small for most modern gravimeters. For accurate gravimetric data, this small amount must be 
estimated and eliminated from relative gravity measurements. All gravimeters drift. This phenomenal factor could also be caused by mechanical stresses and strains in the mechanism as the gravimeter is moved, subjected to vibrations, knocked, unclamped, reset and subjected to heat stresses.

In this study we investigate the drift characteristics of Lacoste and Romberg (LCR) gravimeter (Model G446) based on gravimetric data collected in 2005. The aim is to determine proper timing of field observations in order to enhance the quality of field data collected in a tropical, coastal environment. Although the Lacoste and Romberg (LCR) gravimeter has a data range of $700 \mathrm{mGals}$ and data resolution of $0.005 \mathrm{mGals}$, one often discovers that as a consequence of wrong usage, aging or mechanical faults, the instrument responds to several "error conditions" which in turn results in abnormal drifts (Nwofor \& Chineke, 2003, p.14). They concluded that the result is a reduction in accuracies of gravimetric data. Drift characteristics pattern may vary form one gravimeter to another under field conditions. In this study we adopted an appropriate observational sequence in order to model the drift characteristics of the gravimeter and therefore, have effective control over the drift of the LCR gravimeter. Three observational procedures are commonly used (Osazuwa, 1992, p. 27). They include leap-frog sequence, ladder sequence and double-closure sequence. In the leap-frog sequence, a forward and backward movement is made between base stations until all the stations are connected in continuous orderly manner. The ladder sequence is similar to climbing a ladder, stopping at any of the steps (stations) and returning to the first along the same route. The double-closure sequence is like arranging the stations in a circular loop, and then observation starts from a known gravity base station and continues round the loop until one ends up at the starting base station.

In this study, we adopted a closed-loop sequence in which the drift base station is reoccupied at the end of the daily survey. This observational procedure is more amenable to the drift characteristics of the instrument, the drift model adopted and the assumption made with regard to linearity in correcting for drift. The assumption of a linear drift is appropriate for daily survey. However, an important factor in obtaining gravity values is determining the earth tide effect as their gravitational effects may be greater than the gravity field variations to be sought (Mickus, 2011, p. 3). Linearity made in correction for drift may fail if tidal effects are not first removed (Milsom, 2003, p. 45. (Fig.1) shows typical linear drift and earth tide curves. The drift of the G446 model is negligible after applying earth-tidal corrections (Osazuwa \& Ajakaiye, 1982, p. 267). Most gravity correction exploits algorithms to remove the tidal effect. These algorithms are general formula that does not reflect the effects of local ocean loading. In a general sense, ocean tide loading is the deformation of the Earth due to the weight of the ocean tides (Riccardi, Berrino, Corrado and Hinder, 2008, p.73). Ocean loading effect is characterized by vertical surface displacement of the gravimeter on the deformed Earth and the redistribution of the Earth masses due to elastic deformation. Perhaps, one of the most important indirect effects is the ocean tides which distort the gravitational field through the direct attraction of the water and further through the distortion of the Earth by the load of water. The gravity tides feel the ocean at great distances (Kanestrom, Horpestad and Navresta, 1977). Tidal models in combination with the ocean loading calculation programs are not sufficient for a complete correction of this effect (Neumeyer, Pino, Dierks, Sun and Pflung, 2005, p.110). Most modern gravimeters include a tidal correction of which the mostly widely used is the Longman's formula. This formula does not remove ocean loading and therefore a residual tidal signals will often be observed on long time series (Lacoste and Romberg Inc., 2004, p. 3). In some cases tidal tables are used; for example, tidal gravity correction for 1993, but this may not be readily available. We therefore, in this study adopt a different method for accounting for the tidal effects; called "observational time window". This technique limits the observations to the linear time window and ensures the validity of the linear drift assumption made in relative gravity measurements. It involves a pre-field observation for monitoring the tide. In this approach, the time limit conforms to the near-linear segment of the characteristic response of the unstable gravimeter. To enhance greater fidelity of the data a method that gives the same gravity values for repeat observations after drift correction and facilitates plotting a simple drift curve for a day's observation was adopted. This is based on cascade model (Osazuwa, 1988, p. 295) for the removal of drift from gravimetric data. This model fulfils the linear drift assumption usually made in gravimetric studies. Thus, gravimetric method of geophysical prospecting requires a methodological combination of both field techniques and data processing (Osazuwa, 2007, p. 121).

\section{Theoretical Framework and Methodology}

The cascade model used for the instrumental drift correction ensures flexibility of field procedure and in routine geophysical survey daily drift correction is generally preferred (Osazuwa, 1988, p. 302). The model is based on simple linear drift assumption. For linear drift condition, the drift rate is given as

$$
\mu=\frac{\left(g_{2-} g_{1}\right)-\left(g_{02}-g_{01}\right)}{t_{2}-t_{1}}
$$


Where $g_{1}$ and $g_{2}$ are the absolute gravity values at the terminating stations of the loop, $g_{01}$ and $g_{02}$ are observed gravity values corresponding to $g_{1}$ and $g_{2}$ at time $t_{1}$ and $t_{2}$ respectively. If the terminating stations are the same station, then $g_{2}-g_{1}=0$ and equation (1) becomes

$$
\mu=\frac{\left(g_{02}-g_{01}\right)}{t_{2}-t_{1}}
$$

If $t_{s}$ is the time for intermediate observation and it is referred to time, $t_{1}$ then the drift correction to observed value at station $\mathrm{s}$ is given as

$$
\delta_{s}=\mu\left(t_{s}-t_{1}\right)
$$

A comprehensive computer program based on cascade model (Osazuwa, 1988, p. 295) for processing raw gravity data was used for the computation of the drift characteristics of the unstable gravimeter.

Prior to gravity data acquisition a pre-field observation of gravity values and time were obtained at the same station to monitor the tide for 48 hours. The gravity observations were plotted against time in hours (Fig. 2). The time corresponding to the linear segment were not affected by tidal effects. The minima and maxima segments of the characteristic curves were strongly affected by the tide. Thus, gravity observations were avoided at these hours.

The Lacoste - Romberg G446 model was used for the data acquisition. John Wahr gave the setup for the meter [Fig. 3] (1996, p. 12). It is designed so that

$$
F=K L
$$

Where $L$ is the total length of the spring.

The spring is called "Zero length spring". That is, it is pretensioned during manufacture and so behaves as if it would contract to zero length if tension is lost. The zero - length spring is weak and maximizes extension. Unstable gravimeters use mechanical instability to exaggerate small movement due to change in gravity. The system has an infinite period and if the beam is at equilibrium for one value of , then it is at equilibrium for every value of . The equilibrium condition is independent of so long as

$$
y=\frac{m g}{k}
$$

If equation (5) does not hold, then the beam, b swings all the way clockwise or counter clockwise until it stops. As the spring is stretched or as it ages, the spring constant $\mathrm{K}$ can change and $F=K L$ becomes

$$
F=K L+d
$$

Where $d$ is some small constant. This causes drifts in measured gravity that can be as large as several hundred Gal per month. Thus, in practice, the meter must be frequently brought back to a base station and recalibrated (Wahr, 1996, p.13). The accuracies of this relative meter are approximately $10-20 \mathrm{Gal}(0.01-0.02 \mathrm{mGal})$.

During data acquisition two gravity stations were reoccupied; the reference base and drift base. The reference base is the point where the value of the gravity field being measured have already been established (Fig.4). This is the absolute gravity base station established by Osazuwa and Ajakaiye (1987, p. 307). It is tied to the IGSN71 (International Gravity Standardization Network 1971). The drift base (fig.4) is the repeat station that marks the start and end of sequence of readings and are used to determine the instrumental drift. During gravity survey gravimeter is read at a base station at a frequency dependent on the drift characteristics of the instrument (Keary et al., 2002, p. 132). Exploiting the general knowledge of the low drift rate of Lacoste and Romberg gravimeters, the drift base was re-occupied only at the start and end of the day using the closed loop sequence. This observational procedure is arranged as follows:

$$
\text { A - B - C - D - A }
$$

Where $\mathrm{B}, \mathrm{C}, \mathrm{D}$ are gravity stations and $\mathrm{A}$ is the drift base station. This procedure is like arranging the stations in such a way that observation starts at the drift base station and ends at the starting base station. To enhance the quality of the data collected and to avoid anomalous drift rate some additional precautions were taken during data acquisition. The gravimeter was prevented from power down. Power down will cause temperature of its element to change drastically by $20^{\circ} \mathrm{K}$ to $40^{\circ} \mathrm{K}$ and eventually the gravimeter will experience a severe temperature shock (Seigel, 1995, p. 23). During leveling of the gravimeter at each station it was ensured that the gravity station was at a firm ground. Thus, adverse locations such as soft ground (swamp, wet clay and sand) 
were avoided. On the two occasions that the gravimeter battery was changed during field work, there was a repeat observation at the station last measured. This change relates to the large difference in supply voltage, at least initially between the two batteries. Series of readings are observed in succession at the station, until there is satisfactory stabilization in readings (Seigel, 1995, p. 24). The gravimeter was shielded from external temperature shock with big umbrella and also from extreme vibrations during transportation.

A tropical, coastal environment (Calabar Flank) in southeastern Nigeria, West Africa became very instructive for this study. The coastal basin lies between lat. $4^{0} 48^{\prime} \mathrm{N}-5^{0} 18^{\prime} \mathrm{N}$ and long. $8^{0} 00^{\prime} \mathrm{E}-8^{0} 36^{\prime} \mathrm{E}$. It is sandwiched between the Nigerian sector of the Niger Delta basin to the west and the Oban Massif to the North (fig.5). During the gravity survey temperature was as high as $33^{\circ} \mathrm{C}$.

\section{Results and Discussion}

The results of daily drift characteristics of the unstable gravimeter (Lacoste and Romberg G446 model) are presented in figs.6-8. These results demonstrate that the linear-drift assumption is compatible with the simple observational field procedure (closed loop sequence). Although assumption of linear drift may not be absolutely correct, it is the best in a situation where the exact drift characteristics of the instrument under field condition and the trend of diurnal pressure and magnetic field variation are not exactly known (Osazuwa, 1988, p.296). The linear assumption in this study is validated by the equal gravity values obtained for the repeat observations after drift correction. Table 1 demonstrates the equal values for the repeat stations for a two day observation of relative gravity values as a typical example. The gravity value (COR GRAV) after drift correction for repeat station (002) are $1877.503 \mathrm{mGal}$ and $1880.045 \mathrm{mGal}$ for the first and second day respectively. This condition is well fulfilled by the cascade model. The main advantage of the cascade model in this study is that making a reference of all measured relative gravity values to same time origin makes it easier to plot a single drift curve for a day's observation (figs. 6-8). The limitation of the cascade model is that it can not be used to obtain drift correction over a length of time greater than a day without combining the layover changes in readings with those changes in reading while on transit (Osazuwa, 1988, p. 302).

In the tropical environment like in Nigeria, the error conditions in Lacoste and Romberg gravimeter are found to be associated with temperature changes (Nwofor \& Chineke, 2003, p. 15). Temperature gradients cause changes in the spring elasticity and the length. The operating chamber temperature for the G446 model used in this study is $51^{0} \mathrm{C}$. This magnitude of chamber temperature could have drastically reduced drift but one of the challenges during field survey was providing adequate temperature shielding in order to maintain the chamber temperature. In the tropics, where erratic and high magnitude temperature variations are common, there seems to be severe limitations in the use of aging Lascote-Ramberg gravimeters for gravity surveys as its temperature compensation may not be adequate (Nwofor \& Chineke, 2003, p. 18). While using the Lacoste and Romberg gravimeter in 1979 it was observed that it experienced a temporary thermal control breakdown when exposed to intense tropical heat (Osazuwa \& Ajakaiye, 1982, p. 267). This led to an unsteady operating temperature.

In the drift curves presented in figs. 6-8, some jumps could be noticed. This is due to mechanical hitch or releases. Theses factors are sometimes inevitable and cause the subsequent readings to be higher or lower than the previous readings. The jumps are called "tares" and are several milligal in magnitude. All relative gravimeters are more or less subject to offsets (tares) due to shock and to changes in drift rate when subjected to severe vibration for long periods of time (Seigel, 1995, p. 22). The magnitude of drift characteristics of the gravimeter used for this study is a function of type and characteristics of the gravimeter, age, usage, external temperature fluctuations and air humidity. Martin Lederer called drift "zeror position" and opined that drift is caused by fading of spring tensions and by uncompensated unshielded external effects (2009, p. 385). All these factors make the drift characteristics of the meter complex and accounts for the variability of the drift values. This is reflected in the mean and standard deviation estimated from the descriptive statistics (table 2) and fig. 9. While the standard deviation is a measure of the absolute variability in the drift characteristics of the gravimeter, the mean is a measure of central tendency. The disparity between the standard deviation $(0.29143 \mathrm{mGal})$ and the mean $(0.05990 \mathrm{mGal})$ is a pointer to the numerous factors that led to the magnitude and type of drift characteristics of the gravimeter. The variability is also manifested from the outliers in the box plot and shows why the distribution is not symmetrical and unimodal. This is further validated by the positive skewness ( $3.0461 \mathrm{mGal}$ ) which made the distribution to be skewed to the right. The standard error of the mean was used to work out the confidence limit. The low value of the standard error $(0.0196 \mathrm{mGal})$ is a reflection of the accurate and precautionary steps taken to account for the drift. Software compensation for long term drift cannot be relied upon to completely remove the effect of instrumental drift (Seigel, 1995, p. 29). Therefore, any residual instrumental drift was compensated for by a procedure of base station readings at the beginning and the end of the day (closed-loop sequence). Thus, there is compatibility between the method of observational procedure in 
the field, the observational time window for monitoring the tidal effect and cascade model employed for the computation of instrumental drift.

\section{Conclusion}

The drift characteristics of the Lacoste and Romberg (model G446) have been adequately accounted for by employing appropriate field procedure, mathematical modeling and limiting the observations to the near-linear time window. A combination of linear time window, the closed loop sequence and the cascade model ensures the fulfillment of linear assumption usually made in the determination of instrumental drift. The variability in the modeled drift and the high standard deviation is a pointer to various factors that could have caused the gravimeter to drift. These factors are external, for example, temperature and instrumental instabilities that caused the dial reading to change with time. The results of the drift correction computed from the cascade model are satisfactory and can be validated from the small standard error and similarity of gravity values at the repeat stations.

\section{References}

Kearey, P. Brooks, M. \& Hill, I. (2002). An introduction to geophysical exploration. (3rd ed.). Oxford: Blackwell science, (chapter 6).

Kanestrom, R., Kare, H. \& Navretad, T. Simultaneous measurements of Earth tides in Oslo and Bergen. [Online] Available: Retieved September 2, 2011 from http: www. Geophysica.fi/pdf/geophysica _1977__14_2 _231_Kanestrom.pdf.

Lacoste-Romberg. (2004). Geophysical tips: The continuity series. 2(1), 1-4.

Lederer, M. (2009). Accuracy of the relative gravity measurement. Acta Geodyn. Geomater. 6 (3), 383-390.

Milson, J. (2003). Field geophysics. (3rd ed.). West Sussex: Wiley, (chapter 2).

Mickus, K. Gravity method: Environmental and Engineering applications. [Online] Available: Retieved September 5, 2011 from http://www.dot.state.fl.us/ statematerialsoffice/ Geotechnical/conference/ material/ mickus.pdf.

Mrlina, J. New processing technique for high accuracy gravity data. [Online] Available: Retrieved September 1, 2011, from http://www.eageseg.org/data/egm2007/ session\% 20C/ C_PP_03.Pdf .

Neumeyer, J. Pino, J. Deirks, O. Sun, H. \& Pflug, H. (2005). Improvement of ocean loading correction on gravity data with additional tide gauge measurements. Journal of geodynamics. 40, 104-111. http://dx.doi.org/10.1016/j.jog.2005.07.012

Nwofor, O. K. \& Chineke, T. C. (2003). Abnormal temperature response of a Lacoste-Romberg gravimeter and procedures for tropical utilization. Newton's Bulletin. 1, 11-27.

Osazuwa, I. B. \& Ajakaiye, D. E. (1982). Effect of chamber temperature variation on the Lacoste and Romberg geodetic gravimeter. Journal of mining and Geology. 19 (1), 266-277.

Osazuwa, I. B. \& Ajakaiye, D. E. (1987). Gravity control network at airports in Nigeria. Journal of Geodynamics. 7, 307-317. http://dx.doi.org/10.1016/0264-3707(87)90016-0

Osazuwa, I. B. (1988). Cascade model for the removal of drift from gravimetric data. Survey Review. 29 (228), 295-303.

Osazuwa, I. B. (1992). Logistics and operational techniques in gravimetric studies. In: Proceedings of the first International conference on surveying and mapping, National cartographic centre, Tehran, Iran (ed.: Tatavus Ghazarian). 2, 15-41.

Osazuwa, I. B. (2007). Reduction of gravimetric data using an integrated computer program. Nigerian Journal of Physics. 19 (1), 121-127.

Riccardi, U. Berrino, G. Corrado, G \& Hinder, J. (2008). Strategies in the processing and analysis of continous gravity record in active volcanic aereas: The case of Mt. Vesuvusius. Annale of Geophsics. 51(1), 67-85.

Seigel, H. O. (1995). A guide to high precision land gravimeter surveys. (2nd ed.). Ontario: Scintrex limited, (chapter 5).

Wahr, J. M. Time-variable gravity from satellites. [Online] Available: Retrieved August 15, 2011 from http://www. Gps. Caltech.edu/changes/ge167/ file/Wahr_gravity -treatise.Pdf. 
Table 1. Observed gravity (OBS GRAV), drift and corrected gravity (COR GRAV).

\begin{tabular}{|c|c|c|c|c|c|c|c|}
\hline \multicolumn{2}{|c|}{ DATE: $\quad 14 / 3 / 5$} & \multicolumn{6}{|c|}{ INSTRUMENT: G446 } \\
\hline \multicolumn{4}{|c|}{ REFERENCE ABSOLUTE GRAVITY OF END POINTS ARE: } & \multirow[b]{2}{*}{$\begin{array}{l}\text { TIME } \\
\text { (hr) }\end{array}$} & \multirow{2}{*}{\begin{tabular}{l}
\multicolumn{1}{c}{ AND } \\
OBS \\
GRAV \\
(mGal)
\end{tabular}} & \multirow{2}{*}{$\begin{array}{l}000 \\
\text { DRIFT }\end{array}$} & \multirow[b]{2}{*}{ COR GRAV } \\
\hline $\begin{array}{l}\text { STATION } \\
\text { NUMBER }\end{array}$ & MAP REF & LAT & LON & & & & \\
\hline 001 & POSTOFFICE & 4.9600 & 8.3215 & 10.55 & 1877.503 & 0 & 1877.503 \\
\hline 002 & ODLG & 5.1306 & 8.3410 & 12.00 & 1879.726 & 0.262 & 1879.464 \\
\hline 001 & POSTOFFICE & 4.9600 & 8.3215 & 12.40 & 1877.929 & 0.425 & 1877.503 \\
\hline 002 & ODLG & 5.1306 & 8.3410 & 13.25 & 1879.843 & 0.379 & 1879.464 \\
\hline 003 & CIK-1 & 5.1166 & 8.3333 & 14.40 & 1879.854 & 1.183 & 1878.67 \\
\hline 004 & CIK-2 & 5.1466 & 8.3483 & 15.15 & 1879.641 & 1.556 & 1878.085 \\
\hline 002 & ODLG & 5.1306 & 8.3410 & 15.25 & 1881.119 & 1.655 & 1879.464 \\
\hline 005 & CIK-3 & 5.1550 & 8.3446 & 15.55 & 1881.747 & 0 & 1881.747 \\
\hline 006 & CIK-4 & 5.1616 & 8.3446 & 16.29 & 1881.428 & 0 & 1881.428 \\
\hline 007 & CIK-5 & 5.1700 & 8.3600 & 16.55 & 1881.321 & 0 & 1881.321 \\
\hline 008 & CIK-6 & 5.1783 & 8.3516 & 17.00 & 1877.386 & 0 & 1877.386 \\
\hline 001 & POSTOFFICE & 4.9600 & 8.3216 & 18.15 & 1877.705 & 0.202 & 1877.503 \\
\hline
\end{tabular}

\begin{tabular}{|c|c|c|c|c|c|c|c|}
\hline DATE: & \multicolumn{3}{|c|}{$17 / 3 / 5$} & \multicolumn{2}{|c|}{ INSTRUMENT:G446 } & \multirow[b]{3}{*}{ DRIFT } & \multirow[b]{3}{*}{ COR GRAV } \\
\hline \multirow{2}{*}{\multicolumn{4}{|c|}{$\begin{array}{l}\text { REFERENCE ABSOLUTE GRAVITY OF END POINTS ARE: } \\
\text { STATION }\end{array}$}} & .000 & .000 & & \\
\hline & & & & $\begin{array}{c}\text { TIME } \\
\text { (hr) }\end{array}$ & $\begin{array}{l}\text { OBS } \\
\text { GRAV } \\
\text { (mGal) }\end{array}$ & & \\
\hline 002 & ODLG & 5.1306 & 8.3410 & 12.18 & 1880.045 & 0 & 1880.045 \\
\hline 009 & CIK-7 & 5.1333 & 8.3416 & 12.40 & 1880.056 & -0.121 & 1880.177 \\
\hline 010 & CIK-8 & 5.0400 & 8.3366 & 13.00 & 1879.3 & -0.225 & 1879.525 \\
\hline 002 & ODLG & 5.1306 & 8.3410 & 13.15 & 1879.737 & -0.308 & 1880.045 \\
\hline 011 & CIK-9 & 5.1050 & 8.3366 & 13.30 & 1898.53 & -0.294 & 1898.824 \\
\hline 012 & CIK-10 & 5.0966 & 8.3433 & 15.29 & 1879.63 & -0.174 & 1879.805 \\
\hline 013 & CIK-11 & 5.0866 & 8.3450 & 15.54 & 1879.747 & -0.149 & 1879.896 \\
\hline 014 & CIK-12 & 5.0783 & 8.3466 & 16.02 & 1879.3 & -0.142 & 1879.442 \\
\hline 015 & CIK-13 & 5.0703 & 8.3498 & 16.17 & 1879.854 & -0.127 & 1879.98 \\
\hline 016 & CIK-14 & 5.0626 & 8.3528 & 16.30 & 1879.63 & -0.113 & 1879.744 \\
\hline 017 & CIK-15 & 5.0546 & 8.3548 & 16.45 & 1879.949 & -0.099 & 1880.048 \\
\hline 018 & CIK-16 & 5.0633 & 8.3566 & 17.00 & 1879.949 & -0.084 & 1880.033 \\
\hline 019 & CIK-17 & 5.0370 & 8.3366 & 17.25 & 1879.97 & -0.059 & 1880.029 \\
\hline 020 & CIK-18 & 5.0350 & 8.3450 & 17.50 & 1879.96 & -0.034 & 1879.994 \\
\hline 021 & CIK-19 & 5.0360 & 8.3466 & 18.05 & 1879.96 & -0.018 & 1879.978 \\
\hline 022 & CIK-20 & 5.0333 & 8.3366 & 18.12 & 1880.066 & -0.012 & 1880.078 \\
\hline 002 & ODLG & 5.1306 & 8.3410 & 18.45 & 1880.066 & 0.021 & 1880.045 \\
\hline
\end{tabular}

Table 2. Summary of descriptive statistics of the drift characteristics

\begin{tabular}{|c|c|c|c|c|c|c|c|c|c|}
\hline Variable & $\mathrm{N}$ & Mean & $\begin{array}{c}\text { SE } \\
\text { Mean }\end{array}$ & StDev & Minimum & Q1 & Median & Q3 & Maximum \\
\hline Drift & 220 & 0.0599 & 0.0196 & 0.2914 & -0.3720 & -0.0178 & 0.000000000 & 0.0368 & 1.6550 \\
\hline
\end{tabular}




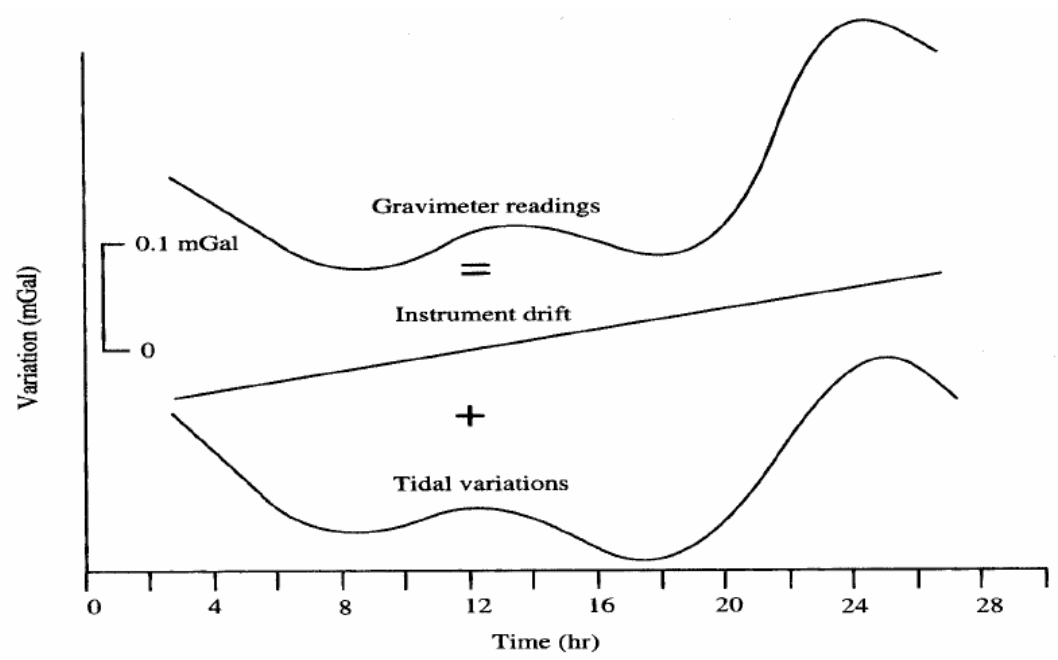

Figure 1. Typical linear drift curve (middle curve) and earth tidal variations (adapted from Burger, 1992)

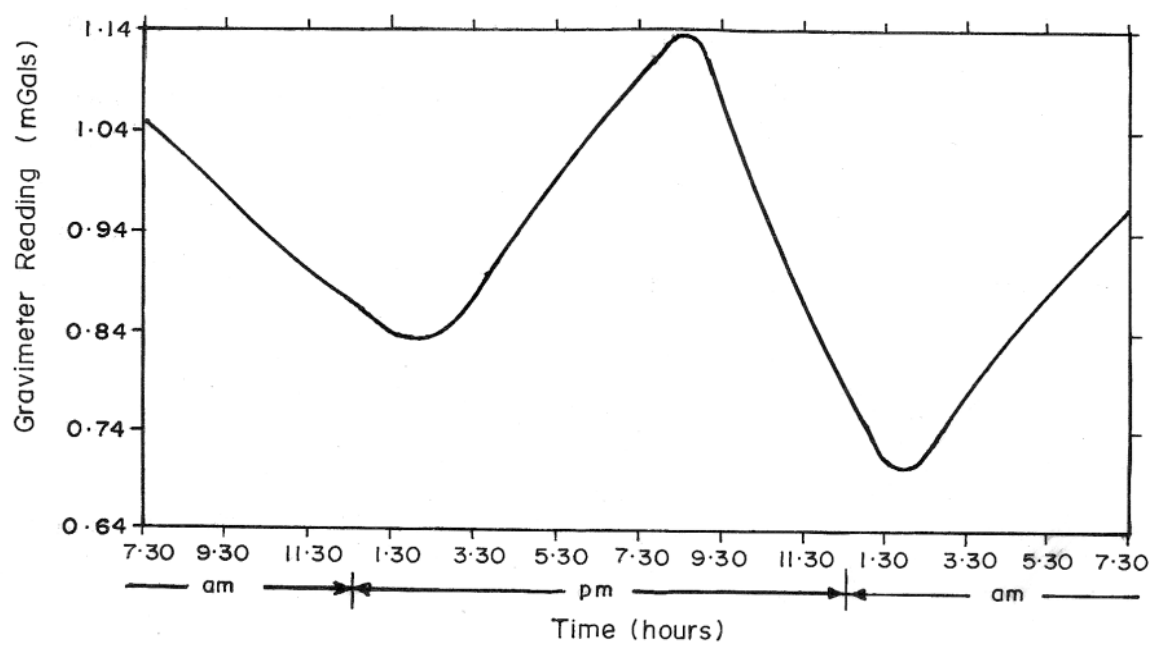

(a)

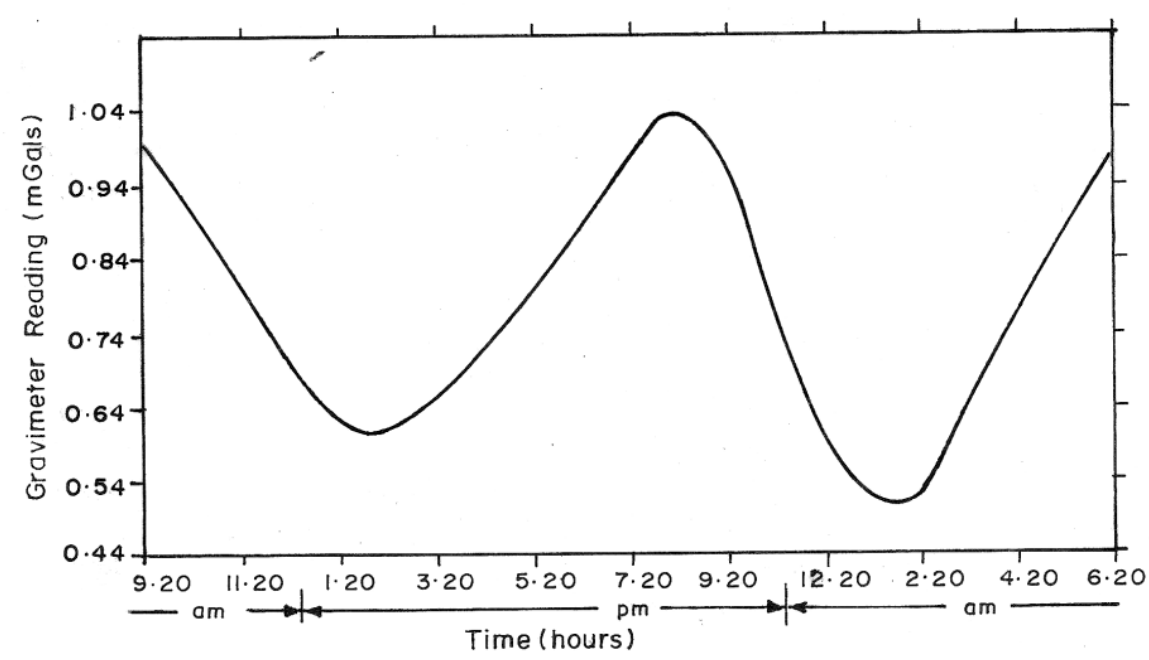

(b)

Figure 2. (a) Observational Time Window for Day 1, (b) Observational Time Window for Day2 


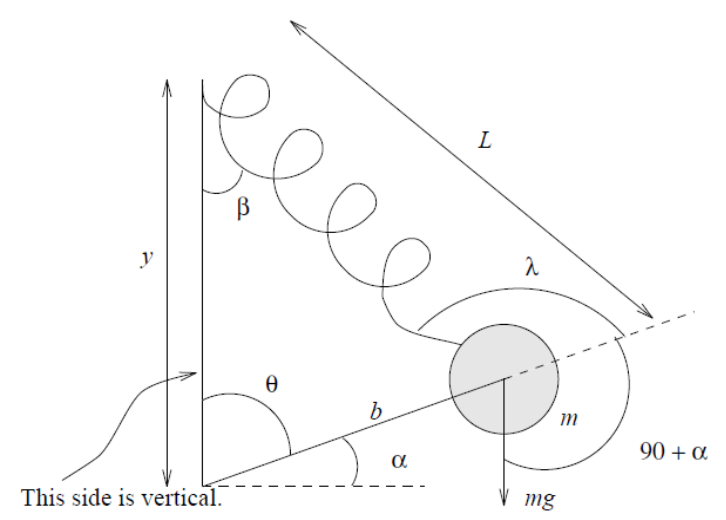

Figure 3. Setup for the Lacoste and Romberg gravimeter
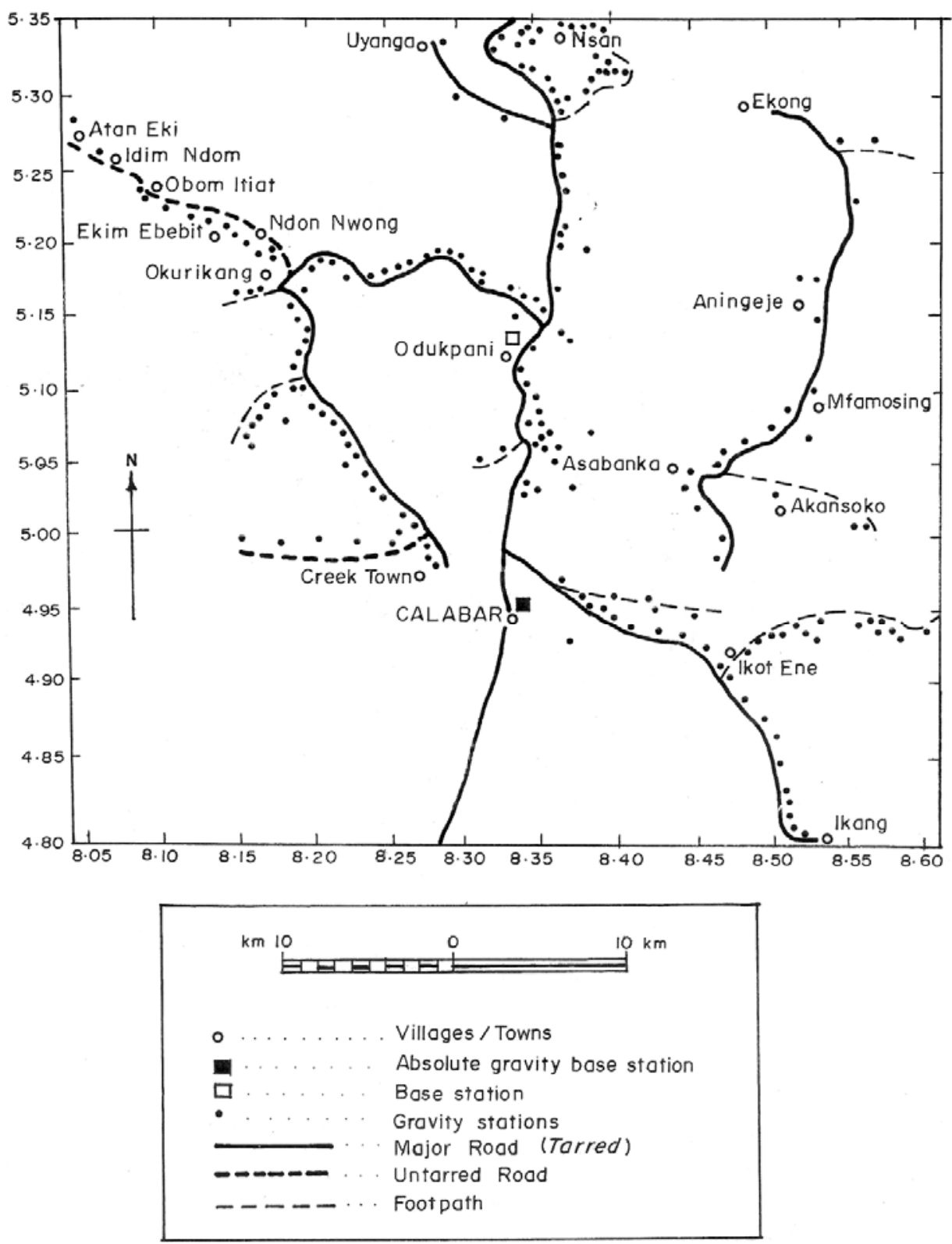

Figure 4. Study area showing gravity stations, reference base and drift base 


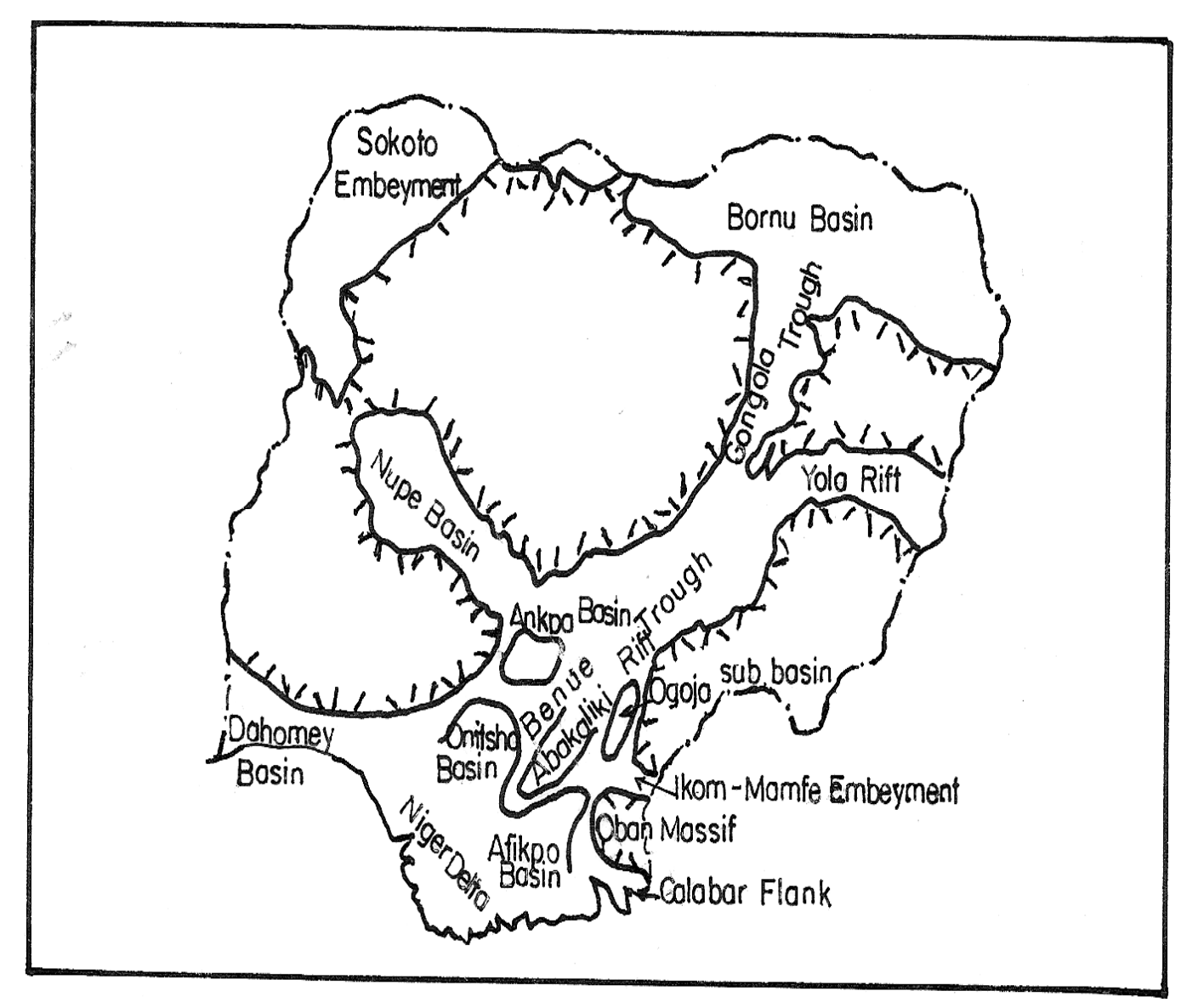

Figure 5. Map of Nigerian sedimentary basin showing the study area 


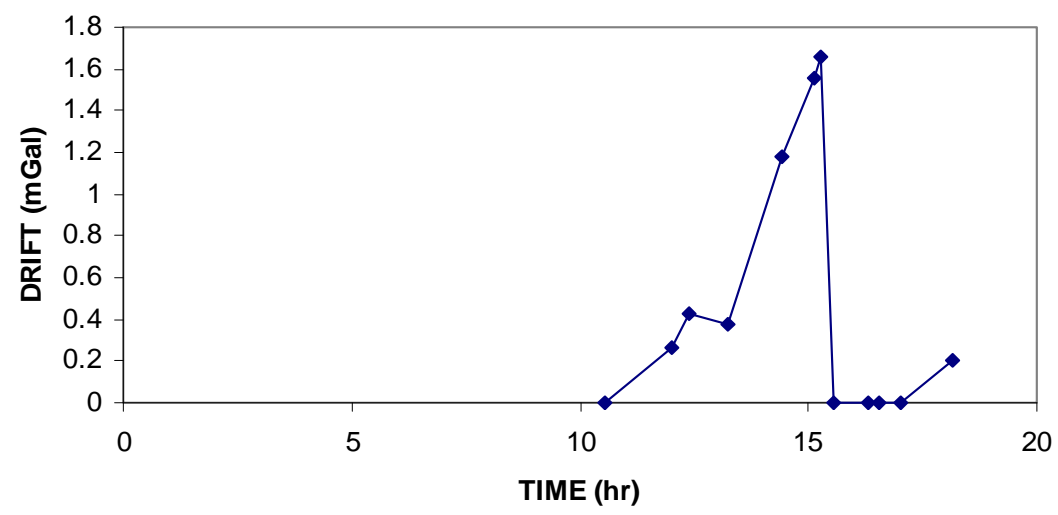

Day one

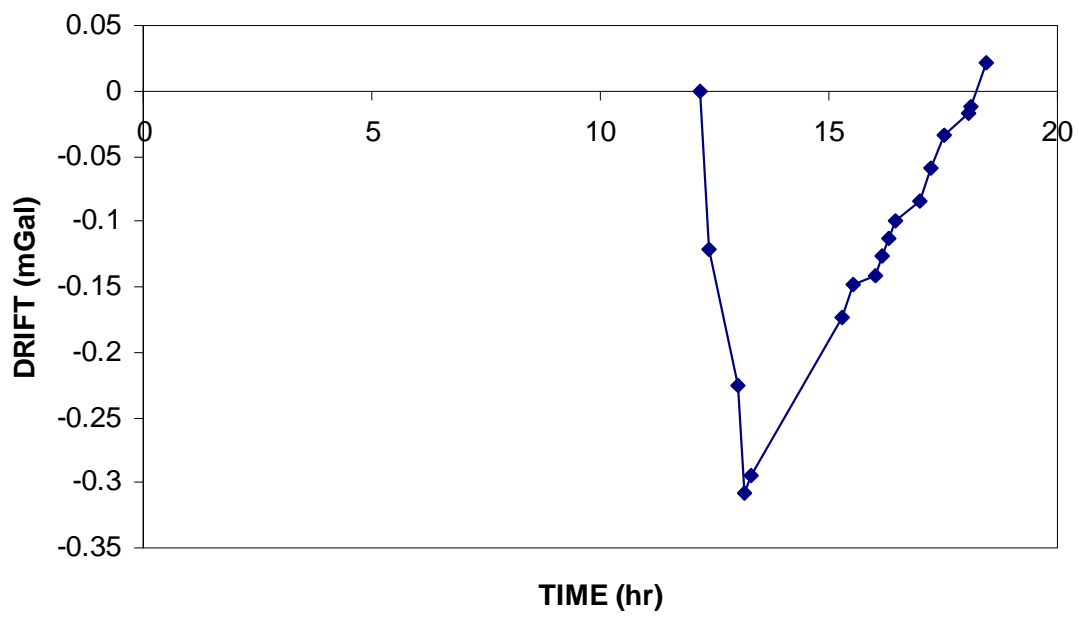

Day two

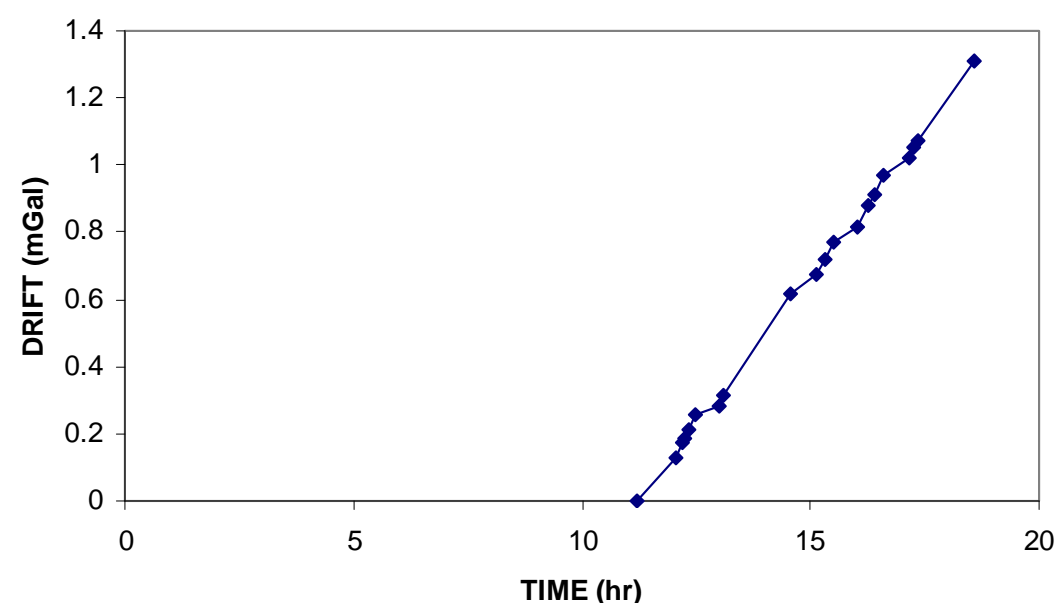

Day three

Figure 6. Drift characteristics for day one, two and three 

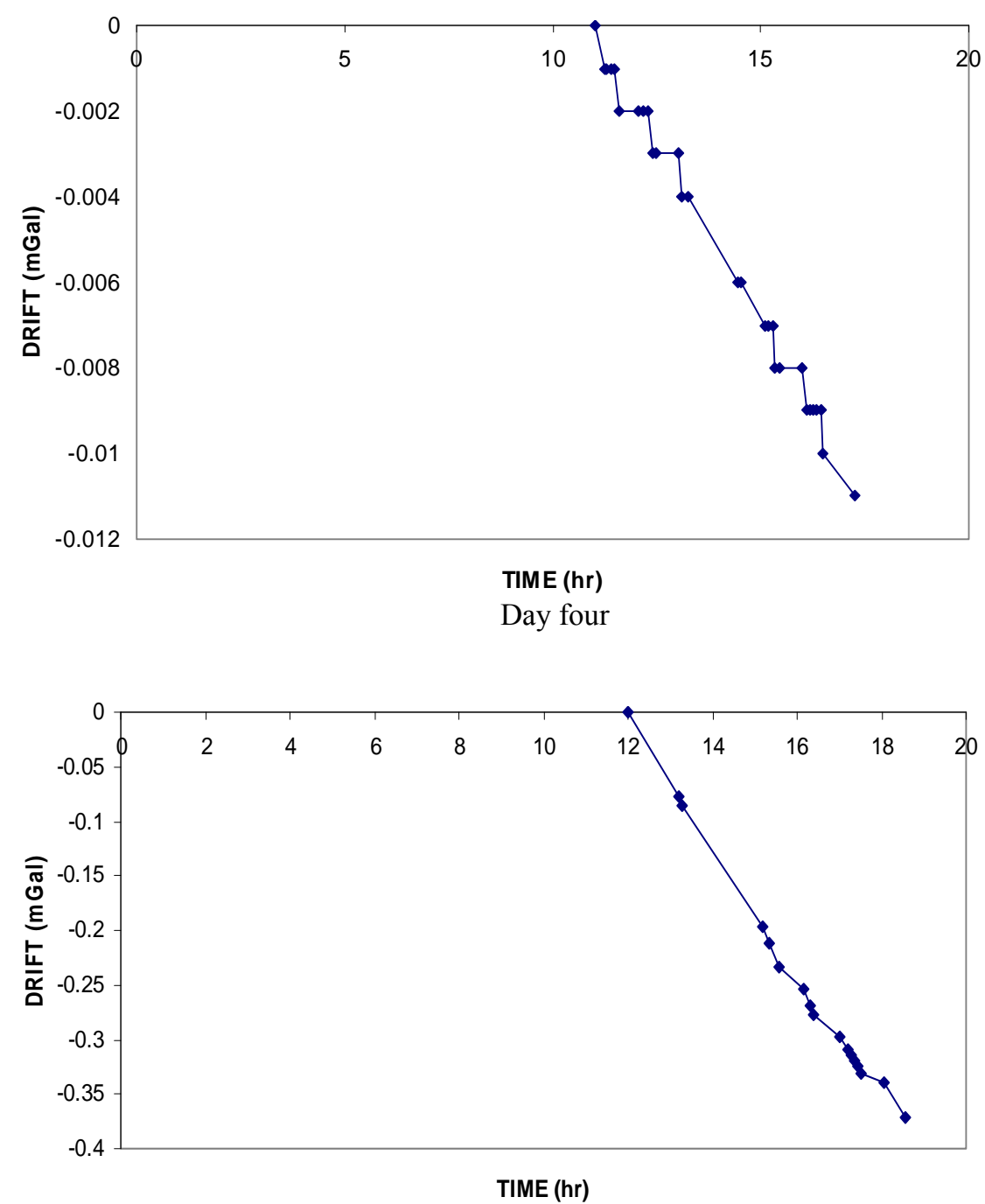

Day five

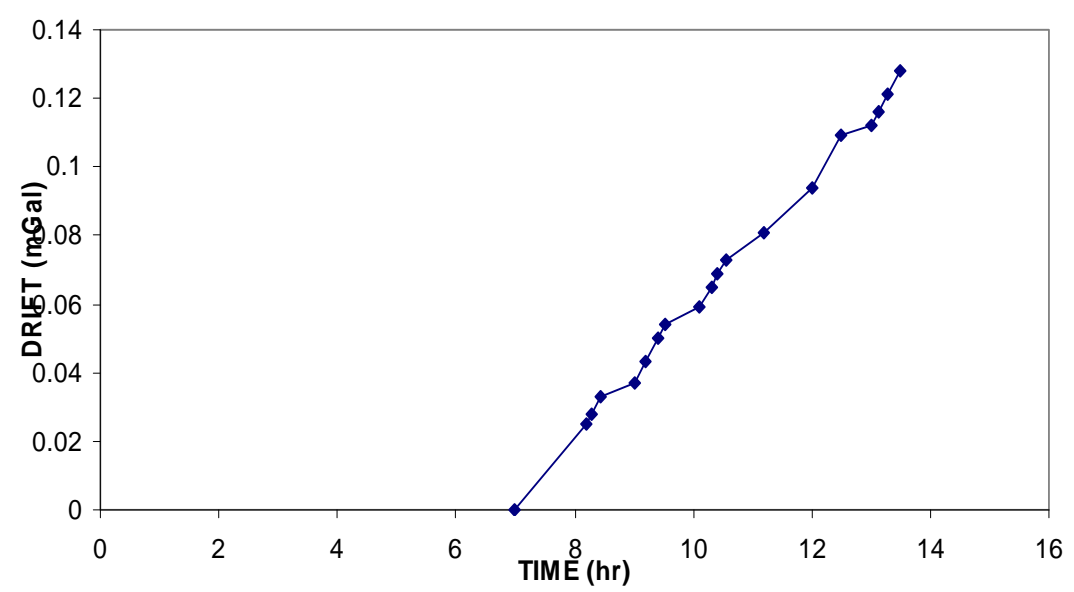

Day six

Figure 7. Drift characteristics for day four, day five and day six 


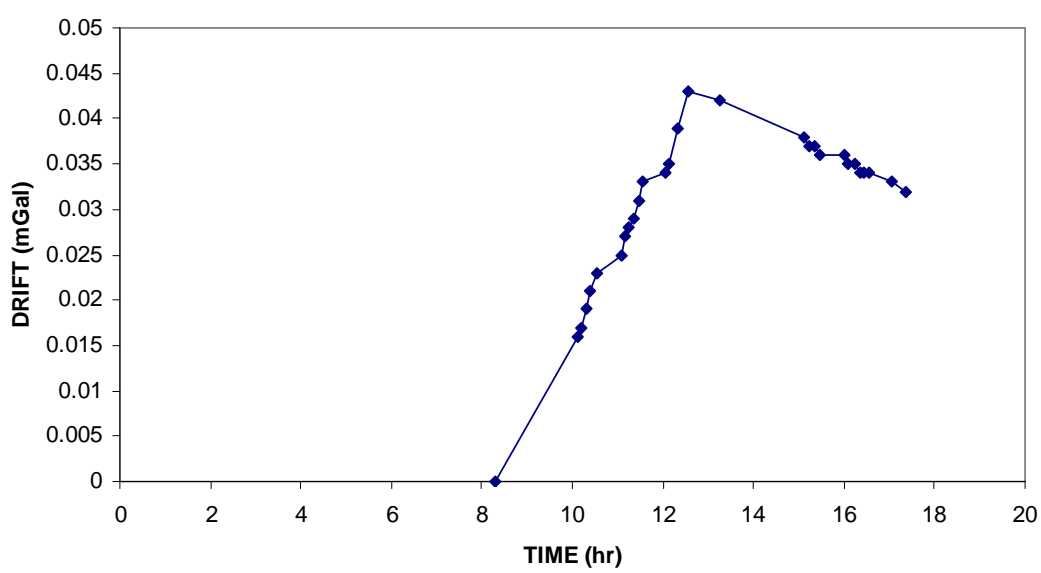

Day seven

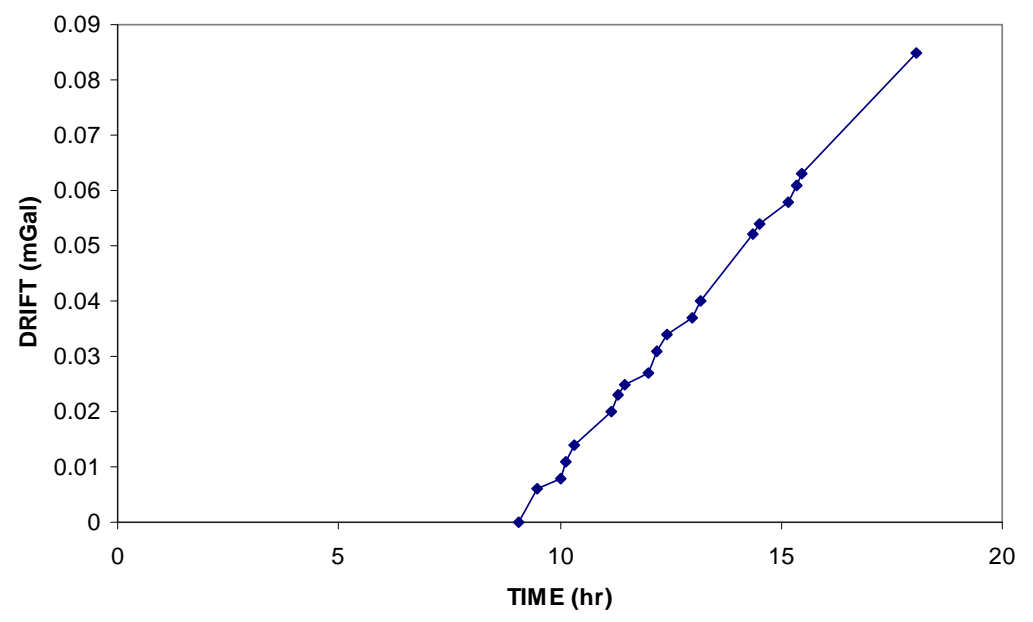

Day Eight

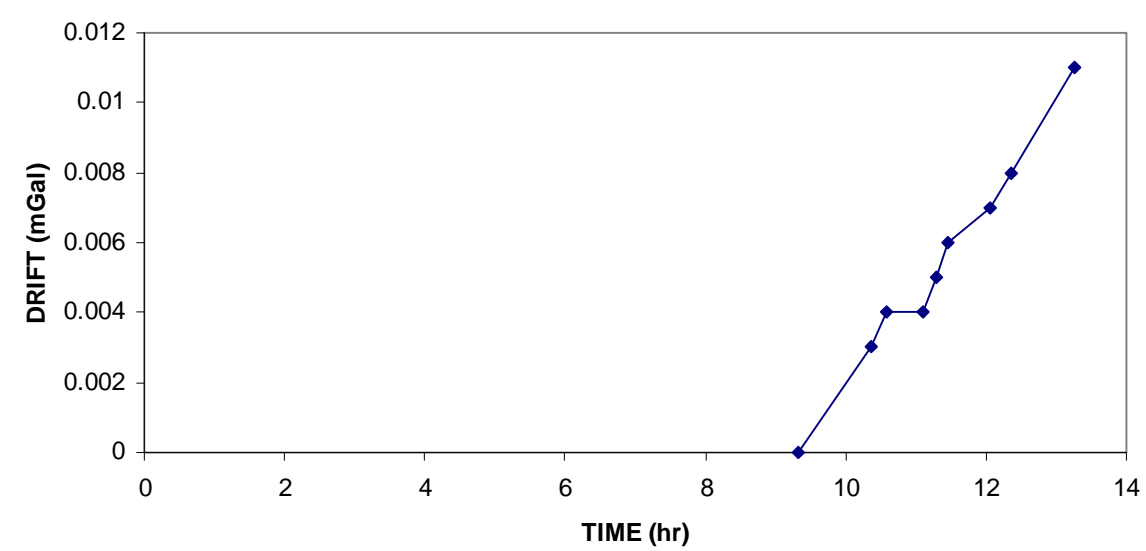

Day nine

Figure 8. Drift characteristics for day seven, eight and nine 


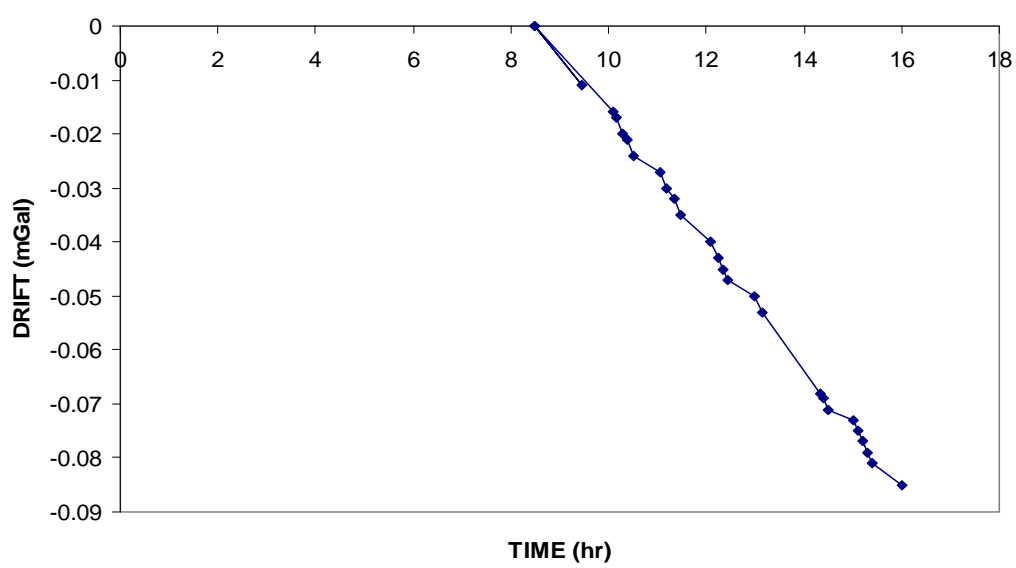

Day ten

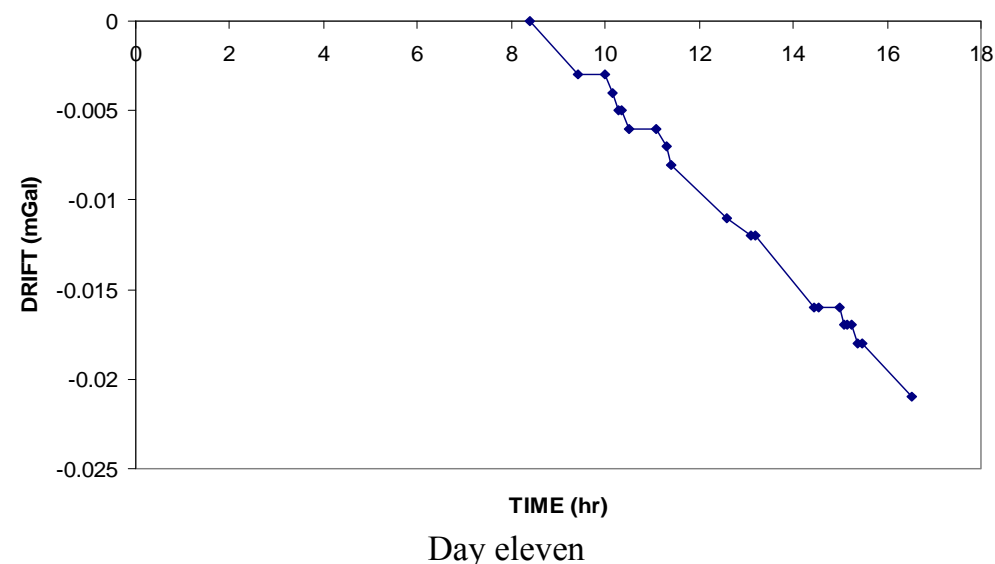

Figure 9. Drift characteristics for day ten and eleven

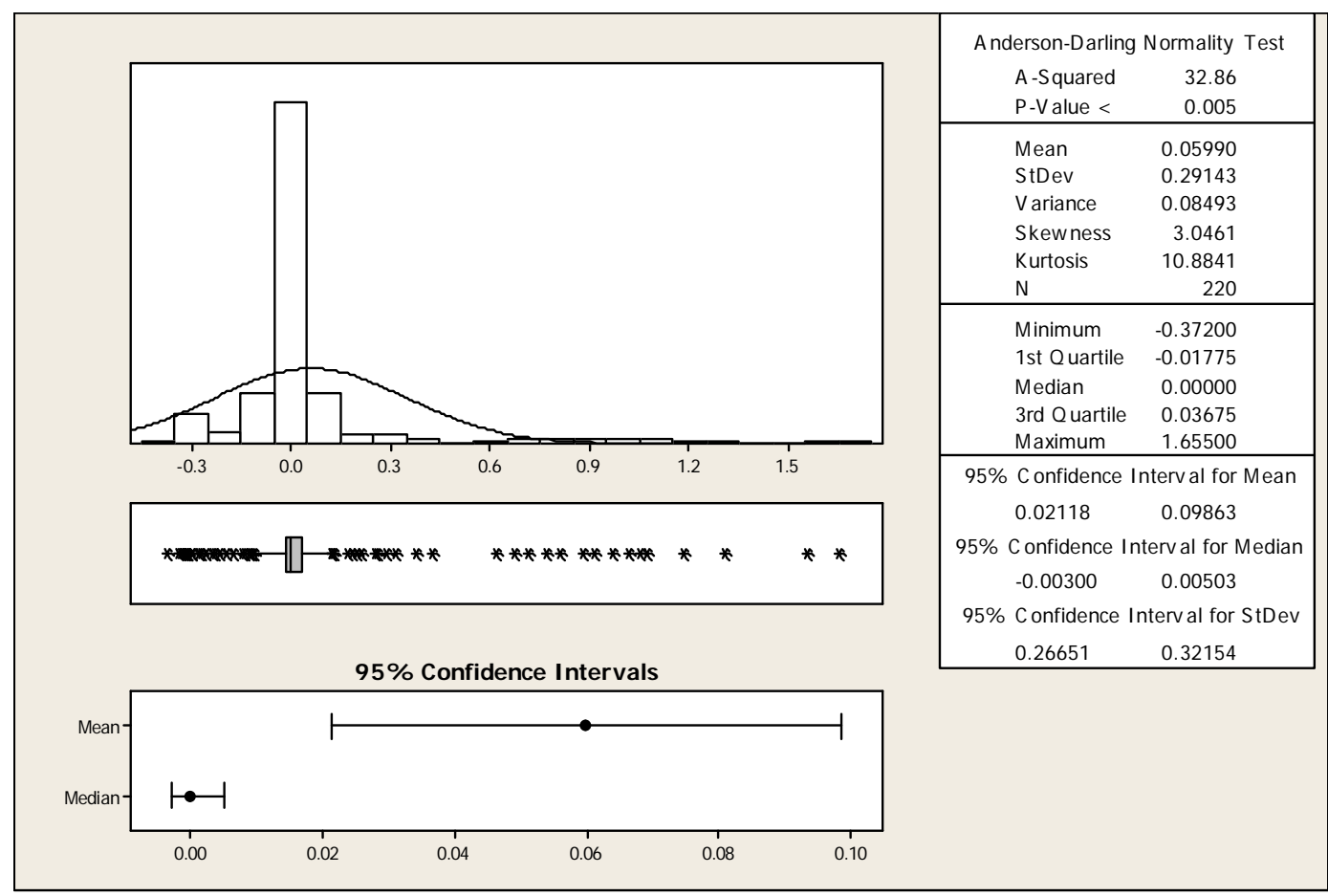

Figure 10. Descriptive statistics of the drift characteristics of the unstable Gravimeter 